\title{
Dynamic Tuning of a Thin Film Electrocatalyst by Tensile Strain
}

\author{
Eric E. Benson, Mai-Anh Ha, Brian. A. Gregg, Jao van de Lagemaat, Nathan R. Neale \& \\ Drazenka Svedruzic*
}

We report the ability to tune the catalytic activities for the hydrogen evolution reaction (HER) and oxygen evolution reaction (OER) by applying mechanical stress on a highly n-type doped rutile $\mathrm{TiO}_{2}$ films. We demonstrate through operando electrochemical experiments that the low HER activity of $\mathrm{TiO}_{2}$ can reversibly approach those of the state-of-the-art non-precious metal catalysts when the $\mathrm{TiO}_{2}$ is under tensile strain. At $3 \%$ tensile strain, the HER overpotential required to generate a current density of $1 \mathrm{~mA} / \mathrm{cm}^{2}$ shifts anodically by $260 \mathrm{mV}$ to give an onset potential of $125 \mathrm{mV}$, representing a drastic reduction in the kinetic overpotential. A similar albeit smaller cathodic shift in the OER overpotential is observed when tensile strain is applied to $\mathrm{TiO}_{2}$. Results suggest that significant improvements in HER and OER activities with tensile strain are due to an increase in concentration of surface active sites and a decrease in kinetic and thermodynamics barriers along the reaction pathway(s). Our results highlight that strain applied to $\mathrm{TiO}_{2}$ by precisely controlled and incrementally increasing (i.e. dynamic) tensile stress is an effective tool for dynamically tuning the electrocatalytic properties of HER and OER electrocatalysts relative to their activities under static conditions.

The ability to alter a materials' structure/function relationship by strain has been widely recognized ${ }^{1}$. Electrocatalytic activities of heterogenous catalysts depend on the surface reactivities toward chemical species along a reaction pathway. Surface reactivities are highly dependent on the surface electronic state, crystal structure and concentration of accessible active sites, all of which can be modulated by surface strain. Several recent reviews summarize theoretical and experimental studies how strain affects electrocatalytic materials ${ }^{2-4}$. Surface strain can be introduced either internally through material architecture (static strain) or by applying an external force (dynamic strain). Static strain in crystalline materials can be introduced by doping ${ }^{5}$, de-alloying ${ }^{6,7}$, annealing $^{8}$, epitaxial growth on a mismatched crystal lattice $\mathrm{e}^{2,3,9,10}$ or by intrinsic surface-stress in $2 \mathrm{D}$ materials ${ }^{11}$. In polycrystalline materials, strain naturally occurs within grain boundaries due to crystals twinning or edge defects. Due to the size confinement, nanomaterials are inherently strained, and that strain can be tuned by preparing nanoparticles with various shapes or sizes ${ }^{2,3}$. For architecturally strained materials, it is often difficult to separate strain-induced effects from chemical or ligand effects ${ }^{12-14}$.

Tuning static strain by varying material architecture is a rather laborious approach since it requires synthesis of a new sample for each discreet amount of strain. The ability to systematically measure materials' structure/ function relationship under precisely controlled and incrementally increasing strain allows one to explore a dynamic range over the strain space without introducing other effects. Experimental studies showing the effects of dynamic strain on electrocatalytic activities have emerged in the literature only recently. A comprehensive review of strained electrochemical systems was published recently ${ }^{15}$. Examples of tunable substrates include elastic materials such as organic polymers ${ }^{16-21}$ and metallic materials such as stainless steel ${ }^{22}$ and pseudoelastic/ shape-memory NiTi alloys ${ }^{23,24}$. Alternatively, external forces have been applied by an atomic force microscopy tip $^{25}$, by introducing subsurface inert gas bubbles ${ }^{26-28}$ or by Li-ion intercalation/deintercalation in battery materi$\mathrm{als}^{6,29-31}$. Application of mechanical, thermal or electrical loading result in bending, compression or expansion of an elastic substrate, further inducing stress-strain response on the deposited material. Such catalyst engineering through dynamic strain has been shown for: i) HER on $\mathrm{MoS}_{2}, \mathrm{Au}, \mathrm{Pt}, \mathrm{Ni}, \mathrm{Cu}, \mathrm{WC}^{16-19}$ and ii) OER on $\mathrm{NiO}_{\mathrm{x}}{ }^{22}$, nickel-iron alloys ${ }^{32}$. The primarily focus of the previous studies was effects of strain on the catalytic activities of transition metals and the experimental results were consistent with d-band theory, described in the seminal work by Mavrikakis et al. ${ }^{33}$. In contrast, effects of strain on catalytic properties of materials with more complex chemical and electronic structures, such as metal oxides, remains poorly understood. In addition to d-band, strain can affect overlap of $\mathrm{d}$ and $\mathrm{p}$ orbitals from metal and oxygen atoms, respectively, thereby inducing $\mathrm{M}-\mathrm{O}$ bond rearrangement and phase transition ${ }^{34,35}$. Strain can also affect formation energies and diffusion pathways 

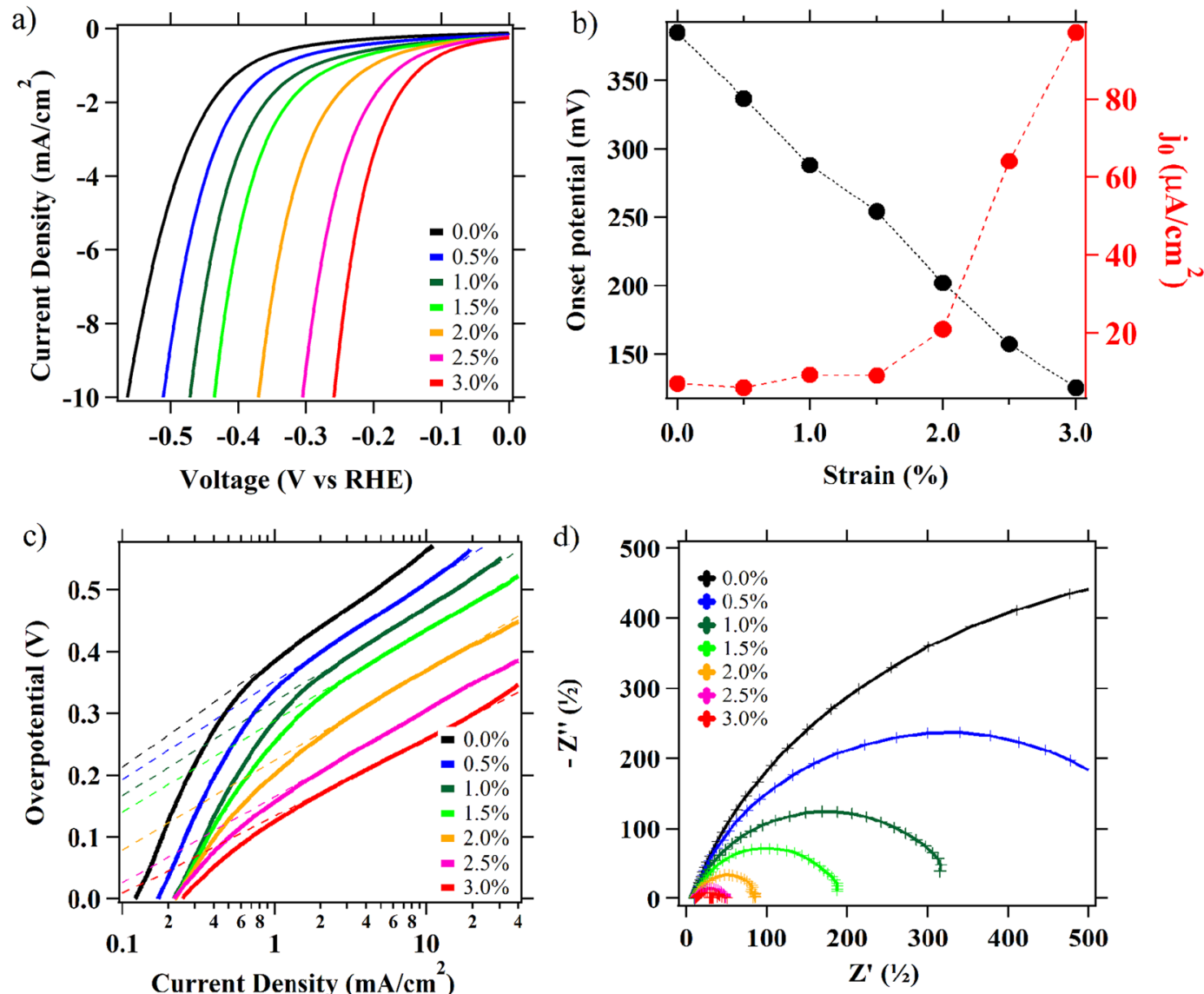

Figure 1. (a) Linear sweep voltammetry (LSV) experiments with $\mathrm{TiO}_{2}$ films in $0.5 \mathrm{M}$ sulfuric acid, at scan rates $50 \mathrm{mV} / \mathrm{s}$. (b) Overpotentials for $1 \mathrm{~mA} / \mathrm{cm}^{2}$ current densities and exchanged current densities determined from Tafel plots are given for comparison. (c) Tafel plots. (d) Electrochemical impedance at $-0.38 \mathrm{~V}$ vs. RHE from $1 \mathrm{~Hz}$ to $100 \mathrm{kHz}$ (Nyquist plots).

of oxygen vacancies $\left(\mathrm{V}_{\mathrm{O}}\right)$, leading to changes in surface reactivities ${ }^{26,36-42}$. While $\mathrm{TiO}_{2}$ has been shown to split water under illumination, a co-catalyst (typically $\mathrm{Pt}$ ) is used to promote catalysis. Although the stochiometric rutile $\mathrm{TiO}_{2}$ surface has low reactivity toward water, theoretical studies suggested that the surface reactivity can be activated by tensile strain ${ }^{37,43}$. Recently, scanning tunneling microscopy (STM) measurements showed increase in hydrogen $\left(\mathrm{H}^{*}\right)$ adsorption energy on stochiometric rutile $\mathrm{TiO}_{2}(110)$ with increase in surface strain ${ }^{26,27}$. Due to the complexity of the system, most of the previous studies were focused on theory and only specific aspects of $\mathrm{TiO}_{2}$ reactivity with water as a function of strain. Considering that strain can affect simultaneously multiple aspects of $\mathrm{TiO}_{2}$ electronic structure and reactivity, it can be expected that each step along a reaction pathway is affected to some degree by strain. Here we show and discuss the effects of dynamic tensile strain on $\mathrm{TiO}_{2} \mathrm{HER}$ and OER activities, based on both experiments and theory. The effects, reported here, are significantly larger than ones observed for transition metals catalysts and trend is reversed.

\section{Results and Discussion}

The experimental set-up used in this study was described in our preceding publication ${ }^{39}$. Briefly, rutile $\mathrm{TiO}_{2}$ thin films are thermally grown on a pseudo-elastic material Nitinol (NiTi intermetallic). Due to the oxophilic nature of titanium, thermal treatment of $\mathrm{NiTi}$ at elevated temperatures under aerobic conditions leads to a nickel-free surface of $\mathrm{TiO}_{2}$. Oxidation of mechanically polished $\mathrm{NiTi}$ at $500^{\circ} \mathrm{C}$ for $30 \mathrm{~min}$ results in a $\sim 50 \mathrm{~nm}$ thick films of rutile $\mathrm{TiO}_{2}(110)$, confirmed by XPS, XRD and Raman spectroscopies ${ }^{39}$. In this work, we find that electrocatalytic results are the most reproducible and effects of strain highest for samples that are never stressed past $3 \%$. For detailed experimental protocols describing sample preparation, application of tensile strain and electrochemical experiments see the Supplemental Information section. The strain applied to the thermally treated, $\mathrm{TiO}_{2}$-coated $\mathrm{NiTi}$ foil is increased at $0.5 \%$ increments from 0 to $3 \%$, (\% corresponds to an increase in electrode surface from its original dimensions). HER catalytic activities were evaluated by steady-state electrochemistry measurements in $0.5 \mathrm{M}$ sulfuric acid aqueous solution with $\mathrm{TiO}_{2}$ films under dynamic tensile strain a $0-3 \%$ (Fig. S1a,b). Linear sweep voltammetry (LSV) results are shown in Fig. 1a. A summary of the electrochemical parameters can be found in Tables 1 and S1. As the samples are strained, the overpotential ( $\eta$, taken as the voltage required to pass $10 \mathrm{~mA} / \mathrm{cm}^{2}$ ) shifts anodically by a remarkable $\sim 320 \mathrm{mV}$ (Fig. 1b). The $\mathrm{TiO}_{2}$ under zero applied strain shows a large Tafel slope $(173 \mathrm{mV} / \mathrm{dec})$ at overpotentials where Tafel behavior is observed and a small exchange current 


\begin{tabular}{|c|c|c|c|c|c|c|}
\hline Strain (\%) & $\begin{array}{l}-\eta(\mathrm{mV}) \text { at } \\
1 \mathrm{~mA} / \mathrm{cm}^{2}\end{array}$ & $\begin{array}{l}-\eta(\mathrm{mV}) \text { at } \\
10 \mathrm{~mA} / \mathrm{cm}^{2}\end{array}$ & $\mathrm{j}_{0}\left(\mathrm{~A} / \mathrm{cm}^{2}\right)$ & $\begin{array}{l}\text { Tafel slope } \\
\text { (mV/dec) }\end{array}$ & $\begin{array}{l}\mathbf{R}_{\mathrm{CT}} \\
(\Omega)\end{array}$ & $\begin{array}{l}\mathrm{C}_{\mathrm{dl}} \\
(\mu \mathrm{F})\end{array}$ \\
\hline 0 & 385 & 565 & $7 \times 10^{-6}$ & 173 & 1108 & 4.1 \\
\hline 1 & 289 & 472 & $9 \times 10^{-6}$ & 155 & 332 & 3.8 \\
\hline 2 & 202 & 371 & $21 \times 10^{-6}$ & 137 & 88 & 5.1 \\
\hline 3 & 125 & 260 & $97 \times 10^{-6}$ & 124 & 39 & 7 \\
\hline Literature $^{47-49}$ & - & $30-340$ & $10^{-2}-10^{-9}$ & $30-50$ & - & - \\
\hline
\end{tabular}

Table 1. HER electrochemical parameters measured for $\mathrm{TiO}_{2}$ electrodes at $0-3 \%$ strain. More information is given in Table S1. HER activities are measured in $0.5 \mathrm{M} \mathrm{H}_{2} \mathrm{SO}_{4}$. EIS measurements are conducted in the frequency range $1 \mathrm{~Hz}$ to $100 \mathrm{kHz}$ at $-0.38 \mathrm{~V}$ vs RHE.

density $\left(\mathrm{j}_{0}=7.0 \mu \mathrm{A} / \mathrm{cm}^{2}\right)$ indicative of a poor HER catalyst (Fig. 1c). At 3\% strain, the Tafel slope decreases to $124 \mathrm{mV} / \mathrm{dec}$ at overpotentials above $100 \mathrm{mV}$ and the exchange current density increases 14 -fold to $97 \mu \mathrm{A} / \mathrm{cm}^{2}$. The Tafel slope of around $120 \mathrm{mV} / \mathrm{dec}$ suggests that the rate limiting steps under those conditions are defined by the Volmer or Volmer-Heyrovsky reaction mechanism (Eqs 1, 2; * denotes a surface site) ${ }^{44}$.

$$
\begin{aligned}
& \text { Volmer step: } \mathrm{H}_{3} \mathrm{O}^{+}+\mathrm{e}^{-}+* \leftrightarrows \mathrm{H} *+\mathrm{H}_{2} \mathrm{O} \\
& \text { Heyrovsky step: } \mathrm{H} *+\mathrm{H}^{+}+\mathrm{e}^{-} \rightleftarrows \mathrm{H}_{2}+*
\end{aligned}
$$

The higher Tafel slopes at low overpotentials are often observed for semiconductors, where charge transfer is mediated by surface states ${ }^{45,46}$. We also conduct electrochemical impedance spectroscopy (EIS) measurements in the frequency range $1 \mathrm{~Hz}$ to $100 \mathrm{kHz}$ at different strain conditions. Nyquist plots (Fig. 1d) show that the high frequency series resistance $\left(R_{S}\right)(\sim 10 \Omega)$ which is normally mostly determined by conduction in the electrolyte does not change significantly with strain, suggesting that strain has no significant effects on the reaction conditions. In contrast, the charge transfer resistance $\left(\mathrm{R}_{\mathrm{CT}}\right)$ decreases systematically from $\sim 1.1 \mathrm{k} \Omega$ to $\sim 40 \Omega$ for 0 to $3 \%$ strain, respectively. The decrease in $\mathrm{R}_{\mathrm{CT}}$ represents an improvement in the reaction kinetics between $\mathrm{TiO}_{2}$ surface and reactants in solution. As can be expected, the observed decreases in $\mathrm{R}_{\mathrm{CT}}$ with strain are inversely proportional to the observed increases in $\mathrm{j}_{0}$. Overall, the measured electrochemical parameters suggest that improved HER activities under strain are due to decreased overpotential $(\eta)$, increased concentration of active surface sites (i.e. higher $\mathrm{j}_{0}$ ) and consequently faster reaction kinetics (i.e. higher $\eta, \mathrm{j}_{0}, 1 / \mathrm{R}_{\mathrm{CT}}$ ). Interestingly, $\mathrm{j}_{0}$ and $1 / \mathrm{R}_{\mathrm{CT}}$ do not linearly vary with strain and more significant changes in electrochemical parameters $\left(\eta, j_{0}, R_{C T}\right)$ occur for strains above $\sim 1.5 \%$ (Fig. 1b, S2a-c). Electrochemical data are consistent with the results we reported previously, where strain raises the energy distribution of $\mathrm{V}_{\mathrm{O}} \mathrm{s}$ (n-type dopants) near the conduction band and causes an increase in carrier concentration density of surface states $\left(\mathrm{SS}_{\mathrm{DOS}}\right)$, with most significant increase between 1-2\% (Fig. S2d) ${ }^{39}$.

In sum, these electrochemical experiments show that straining a rutile $\mathrm{TiO}_{2}$ film transforms it from a poor HER electrocatalyst to a facile one, with activities comparable to activities of other state-of-the-art earth-abundant metal catalysts ${ }^{47-49}$. For example, the HER onset potential at $3 \%$ strain is comparable to these typically reported for molybdenum $\left(\mathrm{MoS}_{2}\right)$ and tungsten sulfides $\left(\mathrm{WS}_{2}\right)\left(\sim 250 \mathrm{mV} \text { at } 10 \mathrm{mV} / \mathrm{cm}^{2}\right)^{49}$, while exchange current densities $\left(\sim 10^{-4} \mathrm{~A} / \mathrm{cm}^{2}\right)$ are significantly higher ${ }^{48,49}$.

Generally, the effects of mechanical strain on any solid material can lead to changes in grain reorganization and/or changes in crystal structure at atomic level. Effects, such as cracking and fissuring of the $\mathrm{TiO}_{2}$ film could in theory improve HER activities by $i$ ) exposing more catalytically active $\mathrm{TiO}_{2}$ crystal facets, edges or defects, ii) increasing the overall electroactive surfaces or $i i i)$ exposing the underlying NiTi substrate. We have explored each of these conceivable circumstances in more detail. First, we note that our prior work on thermally grown rutile $\mathrm{TiO}_{2}$ on Nitinol foils showed elastic behavior, with no cracking at low tensile strain values of $0-5 \%{ }^{39}$. Here we confirm those results by imaging surface morphology with strain using scanning electron microscopy (SEM). SEM images were taken of polished samples, after oxidation at $500{ }^{\circ} \mathrm{C}$, first strained multiple times to $3 \%$ (i.e. elastic range) and then to $7 \%$ (i.e. inelastic range). When strained to $3 \%$ no change in the $\mathrm{TiO}_{2}$ surface morphology is observed (Fig. 2a, insert). However, when samples are strained up to $7 \%$ a change in the surface morphology (fissuring) is observed and large cracks in the surface are visible (Fig. 2b, insert). SEM findings are consistent with the electrochemical data. There are no significant changes in HER activities at $0 \%$ strain for samples that undergo multiple stretch-release cycles up to 3\% and the effects of strain on HER activities were reversible (Fig. 2a). After the first strain-release cycle, small permanent increases in HER activity is observed, likely due to some surface activation process. For samples that are purposely cracked by straining past their elastic limit, some increases in HER activities with strain are observed (Fig. 2b). Nevertheless, increase in HER are less significant than ones presented in Fig. 1a and the effects are irreversible.

Additional evidence that the overall electroactive surface is not increasing significantly with strain is provided by electrochemical analysis. Double layer capacitance $\left(\mathrm{C}_{\mathrm{dl}}\right)$ measurements show that the $\mathrm{C}_{\mathrm{dl}}$ increase only 1.7-fold from 4.1 to $7.0 \mu \mathrm{F}$ when strained from 0 to $3 \%$ (Table 1, Fig. S2b), which is significantly lower than changes in observed HER activities. LSV measurements also are conducted with NiTi substrates that were not thermally treated (i.e., simply the native oxide $\mathrm{NiTiO}_{\mathrm{x}}$ without a thermally grown rutile $\mathrm{TiO}_{2}$ overlayer). For this control we observe a small, reversible increase in HER activities with strain, with about $\sim 10 \mathrm{mV}$ cathodic shift in HER onset potential per $1 \%$ percentage strain (Fig. S4). Although relatively small, the effects of strain on HER activities for untreated $\mathrm{NiTi}$ are still significant and comparable to previous reports on strain-induced changes in HER activities for metallic substrates $\left(5-30 \mathrm{mV} / \% \operatorname{strain}^{17,18}\right)$. For comparison, we see about $\sim 100 \mathrm{mV}$ change 
a)

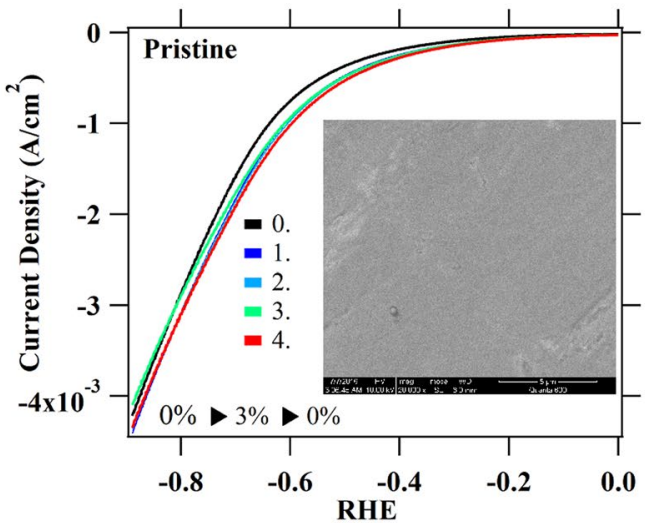

b)

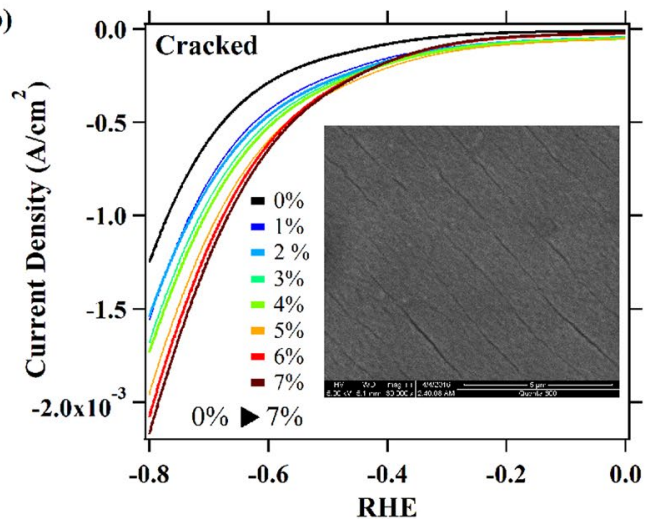

Figure 2. (a) LSV measured with sample that underwent 4 strain-release cycles between 0 and $3 \%$. After each cycle the LSV is measured at $0 \%$ strain. Insert: SEM images of sample strained to 3\%. (b) LSV data for the cracked sample collected for strain incrementally increased 0 to 7\%. Insert: SEM image of sample kept at $7 \%$ strain overnight, after which the sample is released. Obvious surface fissures are visible. All LSV data are collected in $0.5 \mathrm{M} \mathrm{H}_{2} \mathrm{SO}_{4}$.
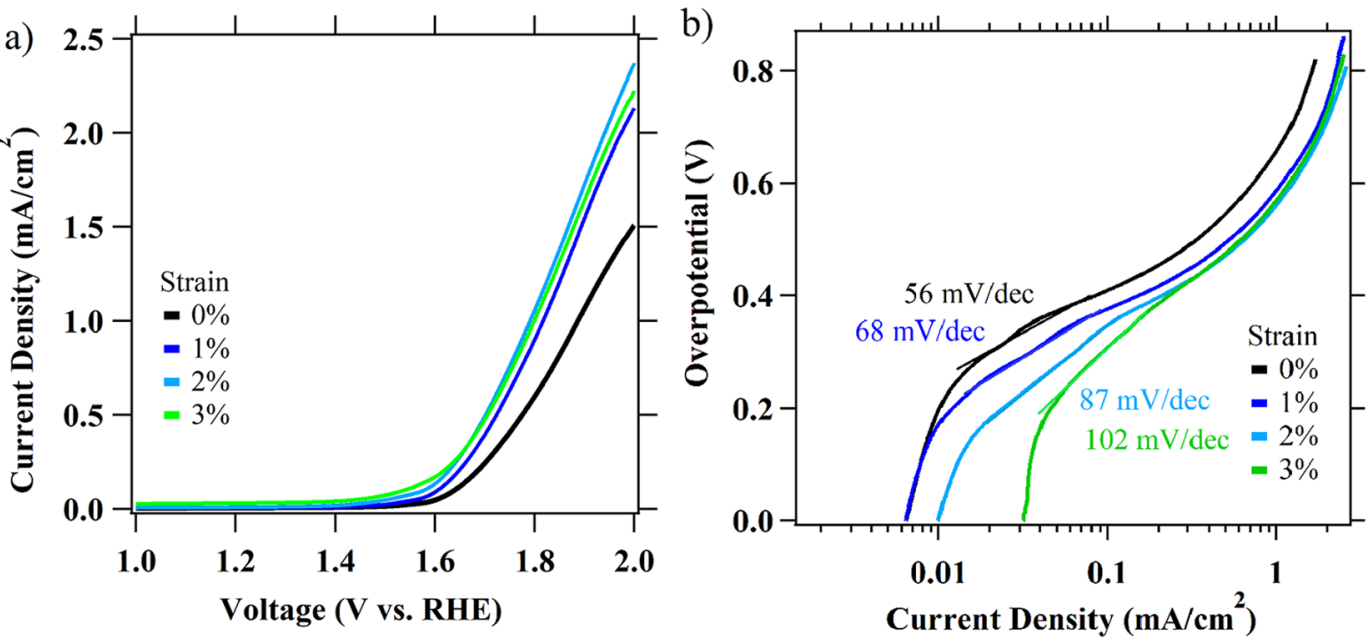

Figure 3. OER activities measured in $1 \mathrm{M} \mathrm{NaOH}$ aqueous solution at scan rates $50 \mathrm{mV} / \mathrm{s}$. (a) Linear sweep voltammetry experiments with $\mathrm{TiO}_{2}$ films under tensile strain (0-3\%) and (b) Tafel plots.

in onset potential per $1 \%$ strain for thermally grown $50 \mathrm{~nm}$ thick $\mathrm{TiO}_{2}$ film. Other electrochemical parameters for untreated $\mathrm{NiTiO}_{\mathrm{x}}$ also are inconsistent with those measured for $\mathrm{TiO}_{2}$ (Table S1). These data make clear that exposure of the $\mathrm{NiTiO}_{\mathrm{x}}$ underlayer via cracking cannot explain increases $\mathrm{in} \mathrm{TiO}_{2} \mathrm{HER}$ activities. In total, these results strongly suggest that $i$ ) opening and closing of surface fissures and exposure of the $\mathrm{NiTiO}_{\mathrm{x}}$ substrate does not explain large improvements in HER activities we have observed; and ii) a continuous $\mathrm{TiO}_{2}$ film is required to observe large, reversible effects of strain suggesting an elastic deformation.

In addition to HER, we also examine the effects of tensile strain (0-3\%) on the rutile $\mathrm{TiO}_{2}$ activity for the OER. LSV measurements in $1 \mathrm{M} \mathrm{NaOH}$ are conducted with $50 \mathrm{~nm}$ thick $\mathrm{TiO}_{2}$ rutile thermally grown on NiTi (Fig. 3a). The LSV curves show large onset potentials ( $\eta$, defined as the potential at an OER current density of $1 \mathrm{~mA} / \mathrm{cm}^{2}$ ) (Table 2) in comparison to other OER catalysts ${ }^{48,49}$. The $\eta$ required to pass $1 \mathrm{~mA} / \mathrm{cm}^{2}$ shifts cathodically $89 \mathrm{mV}$ from 0 to $3 \%$ strain. In comparison to HER activities presented in this work, the observed increases in OER activities with strain are more moderate, but nevertheless comparable to the previous studies on strain-induced effects on OER for different materials ${ }^{6,22,32,38}$. Tafel analysis shows increase in Tafel slope with $0-3 \%$ strain suggesting strain effects OER mechanism (Table 2, Fig. 3b). Significant increases in exchange current densities $\left(\mathrm{j}_{0}\right)$ with increased strain (Table 2, Fig. 3b) are consistent with increased concentration of surface active sites and faster reaction kinetics. Similar to HER results, OER data are consistent with our previous study, where strain raises the energy distribution of $\mathrm{V}_{\mathrm{O}} \mathrm{s}$ (n-type dopants) near the conduction band and causes an increase in carrier concentration density of surface states ( $\left.\mathrm{SS}_{\mathrm{DOS}}\right)^{39}$. Interestingly, Liu et al. observed an opposite trend with pervoskite cobaltite thin films, where OER activities decrease under applied static tensile strain or with introduction of oxygen vacancies ${ }^{50}$. Further increases in OER activities above $3 \%$ strain (Fig. S6) are due to some $\mathrm{TiO}_{2}$ film fissuring. This can be expected considering that surface fissuring exposes $\mathrm{Ni}$, which in its oxidized form $\left(\mathrm{NiO}_{\mathrm{x}}\right)$ is a better 


\begin{tabular}{|l|l|l|l|}
\hline Strain (\%) & $\begin{array}{l}-\eta(\mathbf{m V}) \text { at } \\
\mathbf{1 ~ m A} / \mathbf{c m}^{2}\end{array}$ & $\mathbf{j}_{\mathbf{0}}\left(\mathbf{A} / \mathbf{c m}^{2}\right)$ & $\begin{array}{l}\text { Tafel slope } \\
(\mathbf{m V} / \mathbf{d e c})\end{array}$ \\
\hline 0 & 1.89 & $0.5 \times 10^{-9}$ & 59 \\
\hline 1 & 1.82 & $1.7 \times 10^{-8}$ & 68 \\
\hline 2 & 1.79 & $6.6 \times 10^{-7}$ & 87 \\
\hline 3 & 1.80 & $4.5 \times 10^{-6}$ & 102 \\
\hline
\end{tabular}

Table 2. OER electrochemical parameters measured for $\mathrm{TiO}_{2}$ electrodes at $0-3 \%$ strain. OER activities are measured in $1 \mathrm{M} \mathrm{NaOH}$.

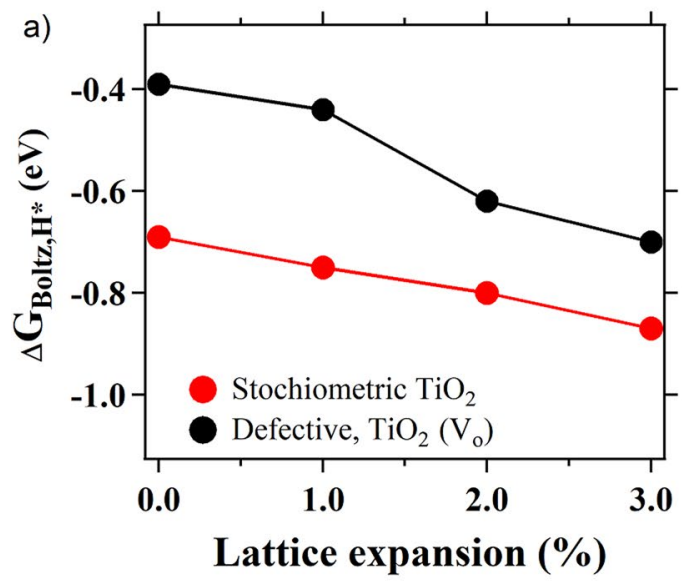

b)

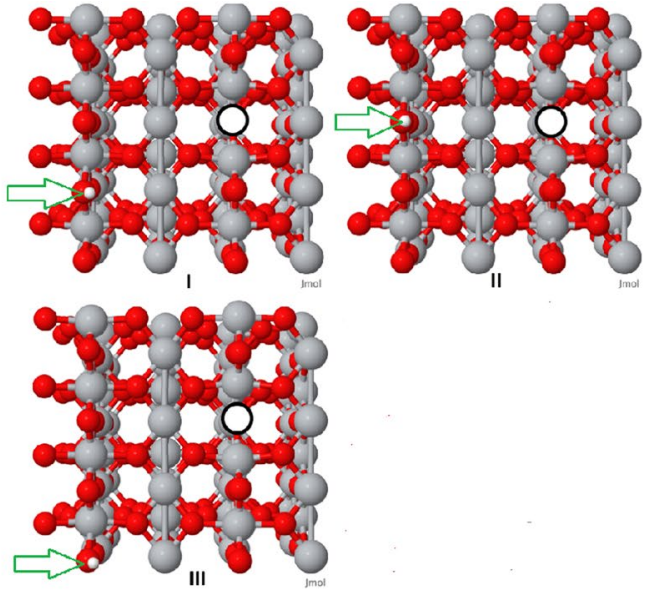

Figure 4. (a) Boltzmann-weighted free energy $\left(\Delta \mathrm{G}_{\mathrm{Boltz}, \mathrm{H}^{*}}\right)$ versus the strain of lattice expansion with the results on the stoichiometric surface in black and the defective surface with an oxygen vacancy $\left(\mathrm{V}_{\mathrm{O}}\right)$ in grey. (b) Local minima of $\mathrm{H}^{*}$ on the defective $\mathrm{TiO}_{2}(110)$ surface. The same minima were found on the strained surfaces, but in a different order with corresponding changes to the relative energies as detailed Table $S 6 . V_{O}$ is denoted by an outlined circle, Ti atoms are gray, oxygen atoms are red, green arrow is added for an easier indentification of $\mathrm{H}^{*}$.

OER catalyst than $\mathrm{TiO}_{2}$ in the alkaline electrolyte investigated here. As with the HER results, for cracked $\mathrm{TiO}_{2}$ surface effects of strain on OER activities are irreversible.

Theory. In our preceding study with $\mathrm{n}$-doped $\mathrm{TiO}_{2}$ films we showed that the tensile strain applied on $50 \mathrm{~nm}$ rutile $\mathrm{TiO}_{2}$ primarily affects the spatial and energetic distribution of oxygen vacancies $\left(\mathrm{V}_{\mathrm{O}} \mathrm{s}\right)^{39}$. Therefore strain-induced changes in the HER and OER catalytic activities are associated with the changes in $\mathrm{V}_{\mathrm{O}} \mathrm{s}$. This is consistent with previous reports showing that bridging $\mathrm{V}_{\mathrm{O}} \mathrm{s}$ are primary active sites for dissociative water adsorption $^{51-54}$. Water dissociation is followed by proton transfer to nearby bridging oxygen atom $\left(\mathrm{OH}_{\mathrm{b}}\right)$ forming two hydroxyl groups for each $\mathrm{V}_{\mathrm{O}}$, and finally diffusion of $\mathrm{OH}_{\mathrm{b}}$ away from the original binding site $\mathrm{s}^{53}$. In contrast to defective $\mathrm{TiO}_{2}$, the surface of stochiometric $\mathrm{TiO}_{2}\left(\mathrm{~s}-\mathrm{TiO}_{2}\right)$ is considered unreactive toward water molecules. However, tensile strain can increase water reactivity on $\mathrm{s}-\mathrm{TiO}_{2}$ by increasing the energy gain upon water adsorption and by decreasing its dissociation barrier ${ }^{37}$.

For most transition metal oxides, the first step in HER mechanism (Eq. 1) is considered a facile chemical reaction. Typically, the common descriptor for HER activities is hydrogen adsorption free energy $\left(\Delta \mathrm{G}_{\mathrm{H}^{*}}\right)$, with the most efficient HER catalysts having $\Delta \mathrm{G}_{\mathrm{H}^{*}}$ approaching 0 (i.e., Sabatier principle). Tensile strain can increase or decrease $\mathrm{H}^{*}$ binding in a manner that depends on a catalyst electronic state (d-band theory for transition metals $)^{33,55}$, as well as an applied overpotential ${ }^{16}$. A previous study with cobalt(II) oxide nanorods, where strain was imposed through nanostructuring, showed that an increase in tensile strain from 0 to $4 \%$ leads to an increase in $\Delta \mathrm{G}_{\mathrm{H}^{*}}$ from negative to positive values, with optimal $\Delta \mathrm{G}_{\mathrm{H}^{*}}$ around $0 \mathrm{eV}$ achieved at $3 \%$ strain ${ }^{40}$. To study $\mathrm{H}^{*}$ adsorption for our system, we performed Plane-Wave Density Functional Theory (PW-DFT) calculations for strained rutile $\mathrm{TiO}_{2}(110)$ surfaces (both stochiometric and defective $\mathrm{TiO}_{2}$ ). Detailed description of the computational methods is given in the Supplemental Information section. Calculations show that the adsorption strength of $\mathrm{H}^{*}$ is weakened in the presence of an $\mathrm{V}_{\mathrm{O}}$ (Table S3,S5) with the local minima of $\mathrm{H}^{*}$ configurations choosing bridging oxygen sites in the row opposite of the $\mathrm{V}_{\mathrm{O}}$ (see Fig. $4 \mathrm{~b}$ for the three most stable $\mathrm{H}^{*}$ configurations). Boltzmann-weighted adsorption free energies plotted against $0-3 \%$ strain are summarized in Fig. $4 \mathrm{a}$ and Table S5. Depending on the strain applied, the lowest three configurations change in stability with concomitant changes in the Boltzmann populations; we note that all three configurations are often nearly degenerate $(<0.5 \mathrm{eV}$ difference in energy) and highly accessible (Fig. 4b, Table S6). In other words, the energetic differences in binding of $\mathrm{H}^{*}$ to $\mathrm{O}_{\mathrm{b}}$ in the row opposite $\mathrm{OV}$ is considerably more stable than a site near the $\mathrm{V}_{\mathrm{O}}$ (configuration IV in Supplemental Information Fig. S9, Table S6 is less stable by $>0.3 \mathrm{eV}$ ). In sum, we found that tensile strain imposed on $\mathrm{TiO}_{2}$ increases both $\mathrm{H}^{*}$ binding (i.e. more negative $\Delta \mathrm{G}_{\mathrm{H}^{*}}$ ) and HER activities measured experimentally. This trend is opposite from the one observed for $\mathrm{CoO}$ nanorods described above, as well as the trend for transition 
metal catalysts where excessive $\mathrm{H}^{*}$ binding impedes HER activities ${ }^{17-19}$. Tafel slopes between 173 and $120 \mathrm{mV} / \mathrm{dec}$ measured in this work (Table 1) are higher than ones reported for $\mathrm{CoO}$ nanorods ${ }^{40}$ as well as most of other transition metal catalysts ${ }^{18,49}$. Higher Tafel slopes suggest different HER mechanism, possibly one with more significant impact of the first Volmer step (Eq. 1). Hypothetically, more negative $\Delta \mathrm{G}_{\mathrm{H}^{*}}$ can improve HER activities by decreasing activation barrier or by improving thermodynamics for $\mathrm{H}^{*}$ formation (Eq. 1, Fig. S10). Alternatively, overall HER rates could be limited by a modest reactivity of water molecules on $\mathrm{TiO}_{2}$ surface, and not $\mathrm{H}^{*}$ binding. Both hypotheses are consistent with higher Tafel slopes determined experimentally and presented computational results. More comprehensive understanding how strain affects HER and OER catalytic mechanisms requires additional computation studies for the entire reaction profile, especially looking at interaction of water molecules with $\mathrm{V}_{\mathrm{O}}$ s. Such calculations are rather complex and would exceed the scope of this publication.

It is important to recognize that effects of strain on $\mathrm{TiO}_{2} \mathrm{HER}$ activities are very complex. Relatively simple theoretical model with single $\mathrm{V}_{\mathrm{O}}$ and single $\mathrm{H}^{*}$ is presented here. Previous reports show that applied strain effects diffusion pathways and overall distribution of $\mathrm{H}^{*}$ s on rutile $\mathrm{TiO}_{2}{ }^{53,56}$. Strain also affects formation, diffusion and energy of $\mathrm{V}_{\mathrm{O}} \mathrm{s}$, as discussed throughout the text. Our calculations show that the formation energy required to create an $\mathrm{V}_{\mathrm{O}}$ decreases with increasing tensile strain from $2.86 \mathrm{eV}$ (unstrained) to $2.51 \mathrm{eV}$ (strained at $3 \%$ ) (Table S2). Therefore, it is likely that strain influences the mechanism of water splitting leading to $\mathrm{H}_{2}$ evolution in more complex ways than simply changing the adsorption strength of $\mathrm{H}^{*}$. Effects of strain on $\mathrm{V}_{\mathrm{O}} \mathrm{S}$ will lead to considerable effects on reaction barriers and pathways to water splitting, where the optimum pathway might differ depending on strain.

\section{Conclusions}

We showed that dynamically straining a thin film of $\mathrm{n}$-doped rutile $\mathrm{TiO}_{2}$ up to $3 \%$ tensile strain using an elastic NiTi substrate significantly increases both HER and OER activities. Significant improvements in HER activities with tensile strain are likely due to an increase in surface active sites and a decrease in kinetic and thermodynamics barriers along the reaction pathway(s). In our preceding work ${ }^{39}$ we showed that tensile strain increased density of surface accessible $\mathrm{V}_{\mathrm{O}} \mathrm{s}$, which is consistent with improved HER and OER activities. We calculate a lower activation barrier for $\mathrm{V}_{\mathrm{O}}$ formation and a stronger binding of the $\mathrm{H}^{*}$ intermediates with strain. This study demonstrates that application of mechanical stress may be a general method for tuning dynamically the catalytic properties of metal oxides.

\section{Methods}

In this work we followed the procedures we published earlier ${ }^{39}$. Briefly, superelastic NiTi foil ( $0.05 \mathrm{~mm}$ thickness) was obtained from Alpha Aesar and cut into $\sim 1 \times 5 \mathrm{~cm}$ samples. The foils were then oxidized at $500^{\circ} \mathrm{C}$ under aerobic conditions for 30 minutes. Oxidized NiTi samples were loaded into an MTI/Fullam SEMTester equipped with a $450 \mathrm{~N}$ capacity load cell and controlled using MTESTQuattro control software. Samples were strained at a rate of $2 \mathrm{~mm} / \mathrm{min}$. Electrochemical measurements were controlled by a CH Instruments $600 \mathrm{D}$ potentiostat using a custom-built single compartment cell with an $\mathrm{Ag} / \mathrm{AgCl}$ reference electrode and platinum counter (Fig. S1a), we have described in our previous publication ${ }^{39}$. For a typical experiment, the cell is loosely assembled around the NiTi sample and then the sample is pre-strained to $5 \mathrm{~N}$, the cell is then tightened onto the sample to create a solution tight cell for electrochemical measurements. To strain the working NiTi electrode, the electrolyte is drained and the cell loosened so that the sample can move freely, and then the strain is adjusted $(2 \mathrm{~mm} / \mathrm{min})$ under software control. The cell is then re-aligned, gently tightened back onto the sample, and the electrolyte is replaced for further measurements. This procedure is repeated at each strain value (Fig. S1b). We observed that electrochemical results were the most reproducible and effects highest for samples that was never stretched pass $3 \%$. To make sure that observed increases in hydrogen evolution reaction (HER) and oxygen evolution reaction (OER) were not due to the electro-deposition of trace amount of platinum on the working electrode from counter Pt electrode, we run control with carbon felt electrode. Silver/silver chloride and mercurous oxide were used as a reference electrode for HER or OER measurements respectively.

Received: 15 July 2019; Accepted: 3 October 2019;

Published online: 04 November 2019

\section{References}

1. Li, J., Shan, Z. \& Ma, E. Elastic strain engineering for unprecedented materials properties. MRS Bulletin 39, 108-114, https://doi. org/10.1557/mrs.2014.3 (2014).

2. Luo, M. \& Guo, S. Strain-controlled electrocatalysis on multimetallic nanomaterials. Nature Reviews. Materials 2, 17059, https://doi. org/10.1038/natrevmats.2017.59 (2017).

3. Yang, S., Liu, F., Wu, C. \& Yang, S. Tuning Surface Properties of Low Dimensional Materials via Strain Engineering. Small 2016, 4028-4047 (2016).

4. Chen, R.-S., Korotcov, A., Huang, Y.-S. \& Tsai, D.-S. One-dimensional conductive IrO2 nanocrystals. Nanotechnology 17, R67 (2006).

5. Clark, E. L., Hahn, C., Jaramillo, T. F. \& Bell, A. T. Electrochemical CO2 Reduction over Compressively Strained CuAg Surface Alloys with Enhanced Multi-Carbon Oxygenate Selectivity. Journal of the American Chemical Society 139, 15848-15857, https://doi. org/10.1021/jacs.7b08607 (2017).

6. Lu, Z. et al. Electrochemical tuning of layered lithium transition metal oxides for improvement of oxygen evolution reaction. Nature Communications 5, 4345, https://doi.org/10.1038/ncomms5345, https://www.nature.com/articles/ncomms5345\#supplementaryinformation (2014).

7. Sethuraman, V. A. et al. Role of Elastic Strain on Electrocatalysis of Oxygen Reduction Reaction on Pt. The Journal of Physical Chemistry C 119, 19042-19052, https://doi.org/10.1021/acs.jpcc.5b06096 (2015).

8. Gu, J. et al. A graded catalytic-protective layer for an efficient and stable water-splitting photocathode. Nature Energy 2, 16192, https://doi.org/10.1038/nenergy.2016.192, https://www.nature.com/articles/nenergy2016192\#supplementary-information (2017). 
9. Stoerzinger, K. A., Choi, W. S., Jeen, H., Lee, H. N. \& Shao-Horn, Y. Role of Strain and Conductivity in Oxygen Electrocatalysis on $\mathrm{LaCoO}_{3}$ Thin Films. The Journal of Physical Chemistry Letters 6, 487-492, https://doi.org/10.1021/jz502692a (2015).

10. Petrie, J. R. et al. Enhanced Bifunctional Oxygen Catalysis in Strained $\mathrm{LaNiO}_{3}$ Perovskites. Journal of the American Chemical Society 138, 2488-2491, https://doi.org/10.1021/jacs.5b11713 (2016).

11. Wang, L. et al. Tunable intrinsic strain in two-dimensional transition metal electrocatalysts. Science 363, 870-874, https://doi. org/10.1126/science.aat8051 (2019).

12. Liu, F., Wu, C. \& Yang, S. Strain and Ligand Effects on $\mathrm{CO} 2$ Reduction Reactions over $\mathrm{Cu}-\mathrm{Metal}$ Heterostructure Catalysts. The Journal of Physical Chemistry C 121, 22139-22146, https://doi.org/10.1021/acs.jpcc.7b07081 (2017).

13. Wang, X. et al. Strain Effect in Bimetallic Electrocatalysts in the Hydrogen Evolution Reaction. ACS Energy Letters 3, 1198-1204, https://doi.org/10.1021/acsenergylett.8b00454 (2018).

14. Kitchin, J. R., Nørskov, J. K., Barteau, M. A. \& Chen, J. G. Role of Strain and Ligand Effects in the Modification of the Electronic and Chemical Properties of Bimetallic Surfaces. Physical Review Letters 93, 156801, https://doi.org/10.1103/PhysRevLett.93.156801 (2004).

15. Zhai, Q. \& Cheng, W. Soft and stretchable electrochemical biosensors. Materials Today Nano 7, 100041, https://doi.org/10.1016/j. mtnano.2019.100041 (2019).

16. Deng, Q., Smetanin, M. \& Weissmüller, J. Mechanical modulation of reaction rates in electrocatalysis. Journal of Catalysis 309, 351-361 (2014)

17. Yan, K., Kim, S. K., Khorshidi, A., Guduru, P. R. \& Peterson, A. A. High Elastic Strain Directly Tunes the Hydrogen Evolution Reaction on Tungsten Carbide. The Journal of Physical Chemistry C 121, 6177-6183, https://doi.org/10.1021/acs.jpcc.7b00281 (2017).

18. Yan, K. et al. The Influence of Elastic Strain on Catalytic Activity in the Hydrogen Evolution Reaction. Angewandte Chemie International Edition 55, 6175-6181, https://doi.org/10.1002/anie.201508613 (2016).

19. Lee, J. H., Jang, W. S., Han, S. W. \& Baik, H. K. Efficient Hydrogen Evolution by Mechanically Strained MoS2 Nanosheets. Langmuir 30, 9866-9873, https://doi.org/10.1021/la501349k (2014).

20. Yang, Y., Adit Maark, T., Peterson, A. \& Kumar, S. Elastic strain effects on catalysis of a PdCuSi metallic glass thin film. Physical Chemistry Chemical Physics 17, 1746-1754, https://doi.org/10.1039/C4CP04924A (2015).

21. Yang, Y. \& Kumar, S. Elastic Strain Effects on the Catalytic Response of Pt and Pd Thin Films Deposited on Pd-Zr Metallic Glass. Journal of Materials Research 32, 2690-2699 (2017).

22. Svedruzic, D. \& Gregg, B. A. Mechano-Electrochemistry and Fuel-Forming Mechano-Electrocatalysis on Spring Electrodes. The Journal of Physical Chemistry C 118, 19246-19251, https://doi.org/10.1021/jp506279q (2014).

23. Du, M., Cui, L., Cao, Y. \& Bard, A. J. Mechanoelectrochemical Catalysis of the Effect of Elastic Strain on a Platinum Nanofilm for the ORR Exerted by a Shape Memory Alloy Substrate. Journal of the American Chemical Society 137, 7397-7403, https://doi. org/10.1021/jacs.5b03034 (2015).

24. Muralidharan, N., Carter, R., Oakes, L., Cohn, A. P. \& Pint, C. L. Strain Engineering to Modify the Electrochemistry of Energy Storage Electrodes. Scientific Reports 6, 27542, https://doi.org/10.1038/srep27542, http://www.nature.com/articles/srep27542/ supplementary-information (2016).

25. Raghuraman, S., Soleymaniha, M., Ye, Z. \& Felts, J. R. The role of mechanical force on the kinetics and dynamics of electrochemical redox reactions on graphene. Nanoscale 10, 17912-17923, https://doi.org/10.1039/C8NR03968B (2018).

26. Li, Z., Potapenko, D. V. \& Osgood, R. M. Controlling Surface Reactions with Nanopatterned Surface Elastic Strain. ACS Nano 9 , 82-87, https://doi.org/10.1021/nn506150m (2015).

27. Potapenko, D. V., Gomes, G. T. \& Osgood, R. M. Correlation of H Adsorption Energy and Nanoscale Elastic Surface Strain on Rutile TiO2(110). The Journal of Physical Chemistry C 120, 21373-21380, https://doi.org/10.1021/acs.jpcc.6b05129 (2016).

28. Gsell, M., Jakob, P. \& Menzel, D. Effect of Substrate Strain on Adsorption. Science 280, 717-720, https://doi.org/10.1126/ science.280.5364.717 (1998)

29. Wang, H. et al. Direct and continuous strain control of catalysts with tunable battery electrode materials. Science 354, 1031-1036, https://doi.org/10.1126/science.aaf7680 (2016).

30. Lu, Z., Jiang, K., Chen, G., Wang, H. \& Cui, Y. Lithium Electrochemical Tuning for Electrocatalysis. Advanced Materials 30, 1800978-1800986 (2018).

31. Wang, H. et al. Electrochemical tuning of vertically aligned $\mathrm{MoS}_{2}$ nanofilms and its application in improving hydrogen evolution reaction. Proceedings of the National Academy of Sciences 110, 19701-19706, https://doi.org/10.1073/pnas.1316792110 (2013).

32. Wang, A. et al. Tuning the oxygen evolution reaction on a nickel-iron alloy via active straining. Nanoscale 11, 426-430, https://doi. org/10.1039/C8NR08879A (2019)

33. Mavrikakis, M., Hammer, B. \& Nørskov, J. K. Effect of Strain on the Reactivity of Metal Surfaces. Physical Review Letters 81, 2819-2822 (1998).

34. Kushima, A., Yip, S. \& Yildiz, B. Competing strain effects in reactivity of $\mathrm{LaCoO}_{3}$ with oxygen. Physical Review B 82, 115435, https:// doi.org/10.1103/PhysRevB.82.115435 (2010).

35. Muralidharan, N. et al. Tunable Mechanochemistry of Lithium Battery Electrodes. ACS Nano 11, 6243-6251, https://doi. org/10.1021/acsnano.7b02404 (2017).

36. Shu, D.-J., Ge, S.-T., Wang, M. \& Ming, N.-B. Interplay between External Strain and Oxygen Vacancies on a Rutile $\mathrm{TiO}_{2}(110)$ Surface. Physical Review Letters 101, 116102 (2008).

37. Yang, L., Shu, D.-J., Li, S.-C. \& Wang, M. Influence of strain on water adsorption and dissociation on rutile $\mathrm{TiO}_{2}(110)$ surface. Physical Chemistry Chemical Physics 18, 14833-14839, https://doi.org/10.1039/C6CP01106C (2016)

38. Petrie, J. R., Jeen, H., Barron, S. C., Meyer, T. L. \& Lee, H. N. Enhancing Perovskite Electrocatalysis through Strain Tuning of the Oxygen Deficiency. Journal of the American Chemical Society 138, 7252-7255, https://doi.org/10.1021/jacs.6b03520 (2016).

39. Benson, E. E. et al. Semiconductor-to-Metal Transition in Rutile TiO2 Induced by Tensile Strain. Chemistry of Materials 29 , 2173-2179, https://doi.org/10.1021/acs.chemmater.6b04881 (2017).

40. Ling, T. et al. Activating cobalt(II) oxide nanorods for efficient electrocatalysis by strain engineering. Nature Communications 8 , 1509, https://doi.org/10.1038/s41467-017-01872-y (2017).

41. Wang, Z.-W., Shu, D.-J., Wang, M. \& Ming, N.-B. Strain effect on diffusion properties of oxygen vacancies in bulk and subsurface of rutile $\mathrm{TiO}_{2}$. Surface Science 606, 186-191, https://doi.org/10.1016/j.susc.2011.09.014 (2012).

42. Zheng, Y.-F., Chen, S., Yang, J.-H. \& Gong, X.-G. Polaron-enhanced giant strain effect on defect formation: The case of oxygen vacancies in rutile $\mathrm{TiO}_{2}$. Physical Review B 99, 014113, https://doi.org/10.1103/PhysRevB.99.014113 (2019).

43. Shi, Y. et al. Role of Surface Stress on the Reactivity of Anatase $\mathrm{TiO}_{2}(001)$. The Journal of Physical Chemistry Letters 8, 1764-1771, https://doi.org/10.1021/acs.jpclett.7b00181 (2017).

44. Shinagawa, T., Garcia-Esparza, A. T. \& Takanabe, K. Insight on Tafel slopes from a microkinetic analysis of aqueous electrocatalysis for energy conversion. Scientific Reports 5, 13801, https://doi.org/10.1038/srep13801 (2015).

45. Vandermolen, J., Gomes, W. P. \& Cardon, F. Investigation on the Kinetics of Electroreduction Processes at Dark $\mathrm{TiO}_{2}$ and $\mathrm{SrTiO}_{3}$ Single Crystal Semiconductor Electrodes. Journal of The Electrochemical Society 127, 324-328, https://doi.org/10.1149/1.2129664 (1980). 
46. Salvador, P. \& Gutiérrez, C. Mechanisms of Charge Transfer at the Semiconductor-Electrolyte Interface: I. Kinetics of Electroreduction at Dark of and in Aqueous Solution on a Sintered Nb-doped Electrode: Influence of $\mathrm{pH}$. Journal of The Electrochemical Society 131, 326-336, https://doi.org/10.1149/1.2115569 (1984).

47. McCrory, C. C. L. et al. Benchmarking Hydrogen Evolving Reaction and Oxygen Evolving Reaction Electrocatalysts for Solar Water Splitting Devices. Journal of the American Chemical Society 137, 4347-4357, https://doi.org/10.1021/ja510442p (2015).

48. Seh, Z. W. et al. Combining theory and experiment in electrocatalysis: Insights into materials design. Science 355, eaad4998, https:// doi.org/10.1126/science.aad4998 (2017).

49. Roger, I., Shipman, M. A. \& Symes, M. D. Earth-abundant catalysts for electrochemical and photoelectrochemical water splitting. Nature Reviews Chemistry 1, 0003, https://doi.org/10.1038/s41570-016-0003 (2017).

50. Liu, X. et al. Uncovering the Effect of Lattice Strain and Oxygen Deficiency on Electrocatalytic Activity of Perovskite Cobaltite Thin Films. Advanced Science 6, 1801898, https://doi.org/10.1002/advs.201801898 (2019).

51. Schaub, R. et al. Oxygen Vacancies as Active Sites for Water Dissociation on Rutile $\mathrm{TiO}_{2}(110)$. Physical Review Letters 87, 266104, https://doi.org/10.1103/PhysRevLett.87.266104 (2001).

52. Lu, G., Linsebigler, A. \& Yates, J. T. Ti ${ }^{3+}$ Defect Sites on $\mathrm{TiO}_{2}(110)$ : Production and Chemical Detection of Active Sites. The Journal of Physical Chemistry 98, 11733-11738, https://doi.org/10.1021/j100096a017 (1994).

53. Lun Pang, C., Lindsay, R. \& Thornton, G. Chemical reactions on rutile $\mathrm{TiO}_{2}(110)$. Chemical Society Reviews 37, 2328-2353, https:// doi.org/10.1039/B719085A (2008).

54. Pan, X., Yang, M.-Q., Fu, X., Zhang, N. \& Xu, Y.-J. Defective $\mathrm{TiO}_{2}$ with oxygen vacancies: synthesis, properties and photocatalytic applications. Nanoscale 5, 3601-3614, https://doi.org/10.1039/C3NR00476G (2013).

55. Hammer, B. \& Nørskov, J. K. Electronic factors determining the reactivity of metal surfaces. Surface Science 343, 211-220, https:// doi.org/10.1016/0039-6028(96)80007-0 (1995).

56. Hupfer, A. J., Monakhov, E. V., Svensson, B. G., Chaplygin, I. \& Lavrov, E. V. Hydrogen motion in rutile $\mathrm{TiO}_{2}$. Scientific Reports 7 , 17065, https://doi.org/10.1038/s41598-017-16660-3 (2017).

\section{Acknowledgements}

This work was conducted by all co-authors, employees of the Alliance for Sustainable Energy, LLC, the manager and operator of the National Renewable Energy Laboratory for the U.S. Department of Energy (DOE) under Contract No. DE-AC36-08GO28308. Funding provided by the U.S. Department of Energy, Office of Science, Office of Basic Energy Sciences, Division of Chemical Sciences, Geosciences, and Biosciences, Solar Photochemistry Program. The views expressed in the article do not necessarily represent the views of the DOE or the U.S. Government. The U.S. Government retains and the publisher, by accepting the article for publication, acknowledges that the U.S. Government retains a nonexclusive, paid-up, irrevocable, worldwide license to publish or reproduce the published form of this work, or allow others to do so, for U.S. Government purposes.

\section{Competing interests}

The authors declare no competing interests.

\section{Additional information}

Supplementary information is available for this paper at https://doi.org/10.1038/s41598-019-52245-y.

Correspondence and requests for materials should be addressed to D.S.

Reprints and permissions information is available at www.nature.com/reprints.

Publisher's note Springer Nature remains neutral with regard to jurisdictional claims in published maps and institutional affiliations.

Open Access This article is licensed under a Creative Commons Attribution 4.0 International License, which permits use, sharing, adaptation, distribution and reproduction in any medium or format, as long as you give appropriate credit to the original author(s) and the source, provide a link to the Creative Commons license, and indicate if changes were made. The images or other third party material in this article are included in the article's Creative Commons license, unless indicated otherwise in a credit line to the material. If material is not included in the article's Creative Commons license and your intended use is not permitted by statutory regulation or exceeds the permitted use, you will need to obtain permission directly from the copyright holder. To view a copy of this license, visit http://creativecommons.org/licenses/by/4.0/.

(C) The Author(s) 2019 